to the life-work of Sir Francis Galton-to his great idea that the future of mankind lies largely in man's own hands, if he will but pay the same attention to his own reproduction that he gives to that of his cattle and his dogs.

The memorial to Sir Francis has taken the fitting form of a building, with public museum, library and lecture hall, with rooms for research students, for experimental work, and for staff-to be called the Galton Laboratory. The sum required is $\$ 70,000$, of which nearly $\$ 12,000$ have already been subscribed by Sir Francis's personal and scientific friends in this country. Any one wishing to aid in this memorial to a man, scarcely less noteworthy in science than his cousin Charles Darwin, should communicate with Sir Edward Henry Busk, the treasurer to the Francis Galton Memorial Fund, University of London, England.

\section{Karl Pearson}

\section{AN EARLY DISCUSSION OF HEREDITY}

I HAVE lately come across a passage which seems worthy of being put on record against the time when the history of opinion and discovery in the science of heredity comes to be written. It is to be found in a work entitled "The Religion of Nature Delineated," by William Wollaston, some time of Sidney Sussex College at Cambridge, a member of the distinguished family which has contributed so largely to scientific knowledge. In Section VIII. of that work, dealing with "Truths Concerning Families and Relations," the author argues that the affection which determines the sense of obligation between relatives is directly dependent upon the intensity of the consanguinity that exists between them. Such consanguinity is regarded as a physical relation which decreases in geometrical proportion with each succeeding generation. The passage would appear to be an adumbration of the views subsequently elaborated by Francis Galton and others. I know of no earlier statement of the quantitative aspect of hereditary phenomena, but should such be known to any of your readers I should be grateful for the reference. The passage transcribed below is taken from a copy of the sixth edition of Wollaston's work which was published in 1738. The book originally appeared in 1722 .

The foundation of all natural relation is laid in marriage. For the husband and wife having solemnly attached themselves each to other, having the same children, interests, etc., become so intimately related as to be reckoned united, one fiesh, and in the laws of nations many times one person. Certainly they are such with respect to the posterity, who proceed from them jointly. The chitdren of this couple are related between themselves by the mediation of the parents. For every one of them being of the same blood with their common parents, they are all of the same blood (truly consanguinei), the relations, which they respectively bear to their parents, meeting there as in their center. This is the nearest relation that can be, next to those of man and wife, parents and their children, who are immediately related by contact or rather continuity of blood, if one may speak so. The relation between the children of these children grows more remote and dilute, and in time wears out. For at every remove the natural tincture or sympathy may be supposed to be weakened; if for no other reason, yet for this. Every remove takes off half the common blood derived from the grandparents. For let $C$ be the son of $A$ and $B, D$ the son of $C, E$ of $D, F$ of $E$ : and let the relation of $C$ to $A$ and $B$ be as 1 : then the relation of $D$ to $A$ and $B$ will be but $\frac{1}{2}$; because $C$ is but one of the parents of $D$, and so the relation of $D$ to $A$ and $B$ is but the half of that, which $C$ bears to them. By proceeding after the same manner it will be found, that the relation of $E$ to $A$ and $B$ is $\frac{1}{4}$ (or half of the half), of $F \frac{1}{8}$ : and so on. So that the relation, which descendents in a direct line have by blood to their grandparents, decreasing thus in geometrical proportion, the relation between them of collateral lines, which passes and is made out through the grandparents, must soon be reduced to an inconsiderable matter.

If then we suppose this affection or sympathy, when it is permitted to act regularly and according to nature, no reason intervening to exalt or abate it, to operate with a strength nearly proportionable to the quantity or degree of relation, computed as above, we may perhaps nearly discern the degrees of that obligation, which persons related lie under, to assist each other, from this motive.

R. C. Punnett 